Journal of Experimental and Clinical Medicine https://dergipark.org.tr/omujecm

Research Article

J Exp Clin Med

2021; 38(3): 308-311

doi: $10.52142 /$ omujecm.38.3.19

\title{
A study on influence of different phases of menstrual cycle on hematological parameters
}

\author{
Vijayashri Basavaraj HANCHINAL ${ }^{*}$, Ambhuja SAMBRANI ${ }^{\oplus}$, Vineet BALJOSHI
}

Department of Physiology, Karnataka Institute of Medical Sciences, Vidyanagar, Karanataka

Received: $12.01 .2021 \quad$ Accepted/Published Online: 30.01 .2021
Abstract
Menstruation is the most common phenomenon observed in fertile women. Menstrual cycle (MC) is of 3 phases: proliferative phase, secretory
phase and menstruation phase. It is controlled by endocrine system. Natural fluctuations in sex steroid hormones during MC causes changes in
hematological parameters. The aim of the present study to assess the impact of different phases of MC on hematological parameters. The study was
conducted in KIMS, Hubli, from $01^{\text {st }}$ March 2011 to $31^{\text {st }}$ March 2012 . Women aged between $20-30$ years with regular menstrual cycle of $27-30$
days were included in the study. During each visit, the subjects' blood was collected and analyzed using KX-21 SYSMEX for various hematological
parameters. A total of 50 healthy young women were included in the study. On statistical comparing of hematological parameters, hematocrit,
hemoglobin, neutrophil count and eosinophil count showed a significant difference while no statistically significant difference was observed in
RBC, leucocyte count, lymphocyte count, monocyte count, erythrocyte sedimentation rate (ESR) and platelet count between different phases of
MC. To conclude, the hematological parameters during the MC are highly dependent on the phasic changes in the immune response mechanism
and sex steroid hormones.

Keywords: menstrual cycle; hematological parameters; phases of menstrual cycle

\section{Introduction}

Menstrual cycle (MC) is a most common phenomenon observed in fertile women and other primates during their normal reproductive age between menarche and menopause for the purpose of procreation. Menstruation is defined as "periodic and cyclic shedding of progestational endometrium accompanied by loss of blood" (Tindall, 1987). The menstruation lasts about 4-5 days with an estimated 20-80 ml of blood loss. During MC, a series of utero-ovarian [follicular or proliferative phase (PP)] and hormonal events [(luteal or secretory phase (SP)] take place over a period of 21-35 days, with a mean of 28 days. MC is caused by complex interaction between hypothalamus, anterior pituitary gland, ovaries and uterus (Thiyagarajan and Jeanmonod, 2019; Treloar et al., 1970). Hormones acts as a key regulatory factors in the MC, where their secretion is highly influenced by the negative and positive feedback during the follicular and luteal phases.

The naturally occurring cyclic and rhythmic fluctuations in the levels of hormones like progesterone, oestrogen, luteinizing and follicle stimulating hormones during the $\mathrm{MC}$ not only affect oocyte maturation, the endometrial and vaginal environment but are also interrelated with multiple changes in the female body both biochemically and physiologically (Dullo and Vedi, 2008; Usha Rani et al., 2014). These fluctuations largely effect the hemoglobin concentration, platelet count
(Alzahrani and Hassan, 2019), other haematological parameters (Usha Rani et al., 2014), immune responses (Northern et al., 1994; Pehlivanoğlu et al., 2001) and serum electrolytes. Changes in oestrogen and progesterone influences Von Willebrand factor concentrations thus effecting platelet function during MC (Drici et al., 1996). Ovulation and menstruation may cause stress induced increase in levels of 17hydroxycorticosterone which results in eosinopenia. It was reported that fluctuations in ovarian hormones during $\mathrm{MC}$ alters immune cells (Pehlivanoğlu et al., 2001). Estimation of leucocyte count helps in women experiencing severe dysmenorrhea to identify underlying reproductive morbidities. Prolonged and excessive bleeding lead to more blood loss $(>80$ $\mathrm{ml}$ ) may cause anaemia, making it necessary to estimate red blood cells (RBC), hemoglobin and erythrocyte sedimentation rate (ESR) (Malipatil and Patil, 2013). Numerous studies have been undertaken to examine the changes in various types of blood cell counts and hormonal profile in MC, but the results been variable and contradictory. The present study was aimed to analyse and assess the impact of different phases of MC on hematological parameters.

\section{Materials and methods}

\subsection{Study population}

The study was conducted in KIMS, Hubli among 50 healthy 
young women, aged between 20-30 years having regular menstrual cycles from 01st March 2011 to $31^{\text {st }}$ March 2012. The study was approved by Ethical committee of KIMS, Hubli and the study was performed in accordance with declaration of Helsinki. Written informed consent was obtained from patients who participated in this study.

Women with regular menstrual cycle of 27-30 days as by history were included in the study. Women with irregular menstrual cycles, women on any medication or hormonal preparation, any physical illness, women with history of endocrine disorders, bleeding disorders, and excessive bleeding during menstrual phase (MP) were excluded from the study.

\subsection{Data collection and analysis}

Subjects' history, physical and clinical examination was performed thoroughly before recruiting in the study. Data was collected on pre-approved pro-forma. Subjects were instructed to visit the centre during each phase of menstrual cycle i.e., 1 $2^{\text {nd }}$ day of MP, $8^{\text {th }}-10^{\text {th }}$ day of proliferative phase (PP), and $19^{\text {th }}$ $-22^{\text {nd }}$ day of SP.

During each visit, the subjects' blood was collected and analysed using KX-21 SYSMEX - (an automated haematology analyser that uses three detector blocks and two kinds of reagents) for various hematological parameters such as hemoglobin, hematocrit, RBC count, white blood cell (WBC) count, differential count, ESR, and platelet count (Table 1).

Table 1. Hematological parameters analysed using KX-21 SYSMEX

\begin{tabular}{|c|c|c|}
\hline Parameter & Principle & Formula \\
\hline Whole WBC (white blood cells) count & Optical laser technique & WBC count in $1 \mathrm{ml}$ of whole blood \\
\hline LYM \% [WBC-small cell ratio (W-SCR)] & - & Ratio of small cells (lymphocyte) to whole WBC \\
\hline MXD \% [WBC-middle cell ratio (W-MCR)] & - & $\begin{array}{c}\text { Ratio of middle cells (basophil }+ \text { eosinophil }+ \\
\text { monocytes) to whole WBC }\end{array}$ \\
\hline NEUT \% [WBC-large cell ratio (W-LCR)] & - & Ratio of large cells (neutrophils) to whole WBC \\
\hline LYM \# [WBC-small cell count (W-SCC)] & - & Absolute count of small cells (lymphocyte) in $1 \mu l$ \\
\hline MXD \# [WBC-middle cell ratio (W-MCC)] & - & $\begin{array}{l}\text { Absolute count of middle cells (basophil }+ \\
\text { eosinophil }+ \text { monocytes) in whole blood }\end{array}$ \\
\hline NEUT \# [WBC-large cell ratio (W-LCC)] & - & Absolute count of large cells (neutrophils) in $1 \mu \mathrm{l}$ \\
\hline RBC (Red blood cells) & Optical laser technique & RBC count in $1 \mu \mathrm{L}$ of whole blood \\
\hline HGB (Hemoglobin) & $\begin{array}{l}\text { Non cyanide hemoglobin analysis } \\
\text { method }\end{array}$ & Volume (grams) of HGB in $1 \mu \mathrm{L}$ of whole blood \\
\hline HCT (Hematocrit value) & $\begin{array}{l}\text { RBC pulse height detection } \\
\text { method }\end{array}$ & Percentage of whole RBC volume in whole blood \\
\hline Platelet count & Optical laser technique & Platelet count in $1 \mu \mathrm{L}$ of whole blood \\
\hline
\end{tabular}

All the hematological parameters during different phases of menstrual cycle were recorded and statistically analysed using the Student's t-test, $\mathrm{p}<0.05$ was considered significant.

\section{Results}

Fifty healthy women, aged between 20-30 years, who volunteered for the study and fits in to inclusion criteria were selected. As shown in Table 2, subjects' hematological parameters such as hemoglobin, hematocrit, RBC count, total leucocyte count, neutrophil count, eosinophil count, lymphocyte count, monocyte count, ESR, and platelet count at various phases of MC were studied and analysed. Among the various phases, ESR $\left(17.08 \pm 7.2 \mathrm{~mm} /\right.$ at the end of $\left.1^{\text {st }} \mathrm{hr}\right)$ was high in MP, hematocrit $(38.13 \pm 1.98 \%)$, hemoglobin $(12.31 \pm 0.7 \mathrm{~g} / \mathrm{dl}), \mathrm{RBC}$ count $(4.47 \pm 0.4$ million cells $/ \mathrm{cu} \mathrm{mm})$, eosinophil count $(4.20 \pm 1.73 \%)$ and monocyte count $(1.74 \pm 1.77 \%)$ was high in PP, and total leucocyte count (7398 \pm 1376 cells/cu mm), neutrophil count $(60.6 \pm 8.74 \%)$, lymphocyte count $(34.12 \pm 7.68 \%)$, and platelet count (3.01 \pm 0.63 lakh cells/cu mm) was high in SP. On statistical comparison of hematocrit during MP $(37.62 \pm 2.14)$ with that of PP (38.13 \pm 1.98$)$, a significant increase was observed during PP $(\mathrm{P}<0.05)$ while a statistically significant decrease in hemoglobin was observed in SP $(12 \pm 0.6)$ compared PP $(12.31 \pm 0.7 ; \mathrm{P}<0.05)$ and $\mathrm{MP}(12.23 \pm 0.72 ; \mathrm{P}<0.05)$.
Table 2. Hematological parameters in different phases of menstrual cycle

\begin{tabular}{|l|c|c|c|}
\hline $\begin{array}{c}\text { Hematological } \\
\text { parameters }\end{array}$ & $\begin{array}{c}\text { Menstrual } \\
\text { phase } \\
\text { (Mean } \pm \text { SD) }\end{array}$ & $\begin{array}{c}\text { Proliferative } \\
\text { phase } \\
\text { (Mean } \pm \text { SD) }\end{array}$ & $\begin{array}{c}\text { Secretory } \\
\text { phase } \\
\text { (Mean } \pm \text { SD) }\end{array}$ \\
\hline Hematocrit (\%) & $\begin{array}{c}37.6162 \pm \\
2.14\end{array}$ & $38.134 \pm 1.98$ & $37.97 \pm 1.73$ \\
\hline Hemoglobin (g/dl) & $12.23 \pm 0.7$ & $12.31 \pm 0.7$ & $12 \pm 0.6$ \\
\hline $\begin{array}{l}\text { RBC count (million } \\
\text { cells/cu mm) }\end{array}$ & $4.38 \pm 0.36$ & $4.47 \pm 0.4$ & $4.37 \pm 0.31$ \\
\hline $\begin{array}{l}\text { ESR (mm/at the } \\
\text { end of 1st hr) }\end{array}$ & $17.08 \pm 7.2$ & $16 \pm 6.1$ & $16.3 \pm 9.92$ \\
\hline $\begin{array}{l}\text { Total leucocyte } \\
\text { count (cells/cu mm) }\end{array}$ & $7142 \pm 1522$ & $7112 \pm 1399$ & $7398 \pm 1376$ \\
\hline $\begin{array}{l}\text { Neutrophil count } \\
\text { (\% of cells) }\end{array}$ & $59.9 \pm 8.49$ & $55.86 \pm 7.84$ & $60.6 \pm 8.74$ \\
\hline $\begin{array}{l}\text { Eosinophil count } \\
\text { (\% of cells) }\end{array}$ & $4.10 \pm 2.25$ & $4.20 \pm 1.73$ & $3.48 \pm 1.32$ \\
\hline $\begin{array}{l}\text { Lymphocyte count } \\
\text { (\% of cells) }\end{array}$ & $32.36 \pm 7.15$ & $33.72 \pm 6.5$ & $34.12 \pm 7.68$ \\
\hline $\begin{array}{l}\text { Monocyte count }(\% \\
\text { of cells) }\end{array}$ & $1.64 \pm 1.77$ & $1.74 \pm 1.77$ & $1.38 \pm 1.88$ \\
\hline $\begin{array}{l}\text { Platelet count } \\
\text { (lakh cells/cu } \\
\text { mm) }\end{array}$ & $2.96 \pm 0.68$ & $3.00 \pm 0.62$ & $3.01 \pm 0.63$ \\
\hline
\end{tabular}


In case of neutrophil count, a statistically significant differences was observed on comparing MP (59.9 \pm 8.49$)$ with PP $(55.86 \pm 7.84 ; \quad \mathrm{P}<0.05)$ and SP $(60.6 \pm 8.74)$ with PP $(\mathrm{P}<0.001)$ while no statistically significant difference was observed between SP and MP $(\mathrm{P}>0.05)$. A statistically significant decrease in eosinophil count was observed in SP (3.48 \pm 1.32$)$ compared to PP $(4.20 \pm 1.73 ; \quad \mathrm{P}<0.05)$. No statistically significant difference was observed in $R B C$, leucocyte count, lymphocyte count, monocyte count, ESR and platelet count between different phases of MC. The most significant hematological parameters during different phases of MC were presented in Fig.1.

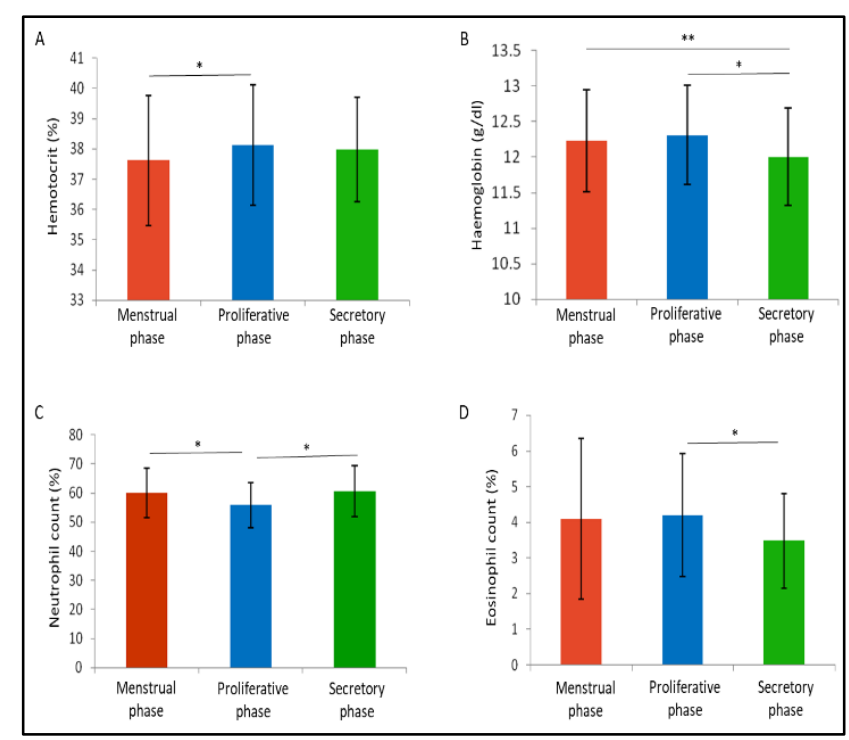

Fig. 1. Comparison of hematological parameters among different phases of menstrual cycle. (A) Hematocrit; (B) Hemoglobin; (C) Neutrophil count; (D) Eosinophil count

\section{Discussion}

Hematological parameters indicates the status of women health and her reproductive capability. The MC and its interrelated cascade mechanisms during the menstrual phases will largely effect the levels of sex steroid hormones and its associated immune mechanisms. In the present study, hematocrit values were statistically significant $(\mathrm{p}<0.05)$ and observed to be high in PP compared to MP and SP which was in accordance with the results of a study by Dapper and Didia (Dapper and Didia, 2002). This might be due to the blood loss during MP of the cycle, leading to a reduction in $\mathrm{RBC}$ and fluctuation in oestrogen and progesterone levels (Dapper and Didia, 2002).

Hemoglobin concentration was decreased significantly in SP compared to MP and PP. Similar results were observed in a study conducted by John Reeves et al, where hemoglobin concentration and hematocrit values were found to be lower in secretory phase which may be due to the expansion of plasma volume (Reeves et al., 2001). In par with the previous studies, no significant change was observed in RBC count during the MC (Harewood et al., 2000). During the ovulatory phase of $\mathrm{MC}$, the level of progesterone begins to rise and oestrogen falls. During SP, both hormones rise again but progesterone peaks high compared to low rise in oestrogen. Oestrogen shows direct effect on hemoglobin and hematocrit, however such effects are antagonised by progesterone by the end of SP (Shilpa et al., 2018). An increase in total leukocyte count in SP compared to MP and PP was observed in the present study, which was in agreement with previous studies (Bouman et al., 2001; Tikare et al., 2008). The increased levels of oestradiol and progesterone in the SP might be playing a role in the deviation of immune response toward a type 2 response (Faas et al., 2000). Estradiol also helps in promoting the release of monocytes and granulocytes from bone marrow. IL-4 was significantly increased in T helper cells in SP as compared with the PP of the cycle. Increase in natural killer cells and cytotoxic $\mathrm{T}$ cells might also be a reason for increased leukocyte counts (Makinoda et al., 1996; Faas et al., 2000). A statistically significant increase in neutrophil count was found in SP compared to MP and PP. This may be due to oestrogen influence on granulocyte proliferation and may be due to promotion of neutrophil release from bone marrow (Molloy et al., 2003).

Levels of circulating eosinophils highly varies during MC due which both eosinopenia and eosinophilia have been reported (Pathak and Kahali, 1957). A significant increase in eosinophil count was found in PP compared to SP. We found a steady increase in lymphocyte count from MP, PP to SP with no statistical significance. Increase in differential lymphocyte count might be a result of large influx of natural killer cells, cytotoxic T cells, and T helper cells (Faas et al., 2000; Van Den Heuvel et al., 2005). Monocytes play a key role in immune responses and their count is highly dependent on the changes in oestrogen and progesterone levels. These hormones induce mitotic arrest, apoptosis in monocytes, and promotion of monocyte release from bone marrow (Thongngarm et al., 2003; Bouman et al., 2005). Monocyte count was increased in PP and decreased in SP in the present study but none were statistically significant.

ESR was found to decrease in PP and SP compared to MP without any statistical significance. This might due to the increased levels of fibrinogen in MP, because of the sudden loss of sex hormonal support and uterine endometrium necrosis during the process of menstruation (Malipatil and Patil, 2013). Increase in fibrinogen concentrations during MP also influences the rouleaux formation and ESR levels (Dapper and Didia, 2002). In our study, an increase in platelet counts was found in PP and SP compared to MP, showing no statistical significance. Our study is in consistent with previously reported studies, where similar pattern of decrease in platelet count was observed in MP compared to PP and SP (Abbott et al., 2010). Variation of platelet count during MC depends on multiple factors such as corticosteroids or due to an endocrine reaction via spleen on hemopoietic system, or toxic resorption of necrotic material from raw endometrial surface, or because of toxic menotoxin reaction, or variations in the levels of ovarian hormones (Kumar Chawla et al., 2010). 
The strengths of the present study is use of automated haematology analyser which helps in reducing manual errors during analysis. The limitation of the study is consideration of comparatively small sample size.

Among all hematological parameters, ESR was high in MP, hematocrit, hemoglobin, RBC, eosinophils, and monocyte count was high in PP, whereas neutrophils, eosinophils, lymphocytes, total leucocytes, and platelet counts were high in SP. This study concludes that the hematological parameters during the MC are highly dependent on the phasic changes in the immune response mechanism and sex steroid hormones

\section{Conflict of interest}

None to declare.

\section{Acknowledgments}

None to declare.

\section{References}

1. Abbott, R., Chandra, M., Chandra, R., 2010. Total platelet count, adhesive platelet count, platelet adhesiveness in normal menstrual cycle and functional uterine bleeding: A comparative study. J. Obstet. Gynaecol. Res. 9, 265-269.

2. Alzahrani, F., Hassan, F., 2019. Modulation of Platelet Functions Assessment during Menstruation and Ovulatory Phases. J. Med. Life. 12, 296-300.

3. Bain, B.J., England, J.M., 1975. Variations in Leucocyte Count During Menstrual Cycle. BMJ. 2, 473-475.

4. Bouman, A., Jan Heineman, M., Faas, M.M., 2005. Sex hormones and the immune response in humans. Hum. Reprod. Update. 11(4):411-23.

5. Bouman, A., Moes, H., Heineman, M.J., De Leij, L.F.M.H., Faas, M.M., 2001. The immune response during the luteal phase of the ovarian cycle: Increasing sensitivity of human monocytes to endotoxin. Fertil. Steril. 76, 555-559.

6. Dapper, D.V.B., Didia, B.C., 2002. Haemorheological changes during the menstrual cycle. East. Afr. Med. J. 79(4):181-3

7. Drici, M.D., Burklow, T.R., Haridasse, V., Glazer, R.I., Woosley, R.L., 1996. Sex hormones prolong the QT interval and downregulate potassium channel expression in the rabbit heart. Circulation. 94, 1471-1474.

8. Dullo, P., Vedi, N., 2008. Changes in serum calcium, magnesium and inorganic phosphorus levels during different phases of the menstrual cycle. J. Hum. Reprod. Sci. 1(2), 77-80.

9. Faas, M., Bouman, A., Moesa, H., Heineman, M.J., De Leij, L., Schuiling, G., 2000. The immune response during the luteal phase of the ovarian cycle: A Th2-type response? Fertil. Steril. 74(5), 1008-1013.

10. Harewood, W.J., Gillin, A., Hennessy, A., Armitstead, J., Horvath, J.S., Tiller, D.J., 2000. The effects of the menstrual cycle, pregnancy and early lactation on haematology and plasma biochemistry in the baboon (Papio hamadryas). J. Med. Primatol. $29,415-420$.

11. Rajnee, A., Binawara, B.K., Choudhary, S., Chawla, V.K., \& Choudhary, R. (2010). Haematological and electrocardiographic variations during menstrual cycle. Pak. J. Physiol. 6(1), 18-21.

12. Makinoda, S., Mikuni, M., Sogame, M., Kobamatsu, Y., Furuta, I., Yamada, H., Yamamoto, R., Fujimoto, S., 1996. Erythropoietin, granulocyte-colony stimulating factor, interleukin- $1 \beta$ and interleukin- 6 during the normal menstrual cycle. Int. J. Gynaecol. Obstet. 55, 265-271.

13. Malipatil, B.S., Patil, S. 2013. Hematological modulation in different phases of menstrual cycle. Int. J. Biomed. Res., 4, 8893

14. Molloy, E.J., O'Neill, A.J., Grantham, J.J., Sheridan-Pereira, M., Fitzpatrick, J.M., Webb, D.W., Watson, R.W.G., 2003. Sexspecific alterations in neutrophil apoptosis: The role of estradiol and progesterone. Blood. 102, 2653-2659.

15. Northern, A.L.D., Rutter, S.M., Peterson, C.M., 1994. Cyclic changes in the concentrations of peripheral blood immune cells during the normal menstrual cycle. SEBM. 207, 81-88.

16. Pathak, C.L., Kahali, B.S., 1957. Cyclic variations in the eosinophil count during the phases of the menstrual cycle. The J. Clin. Endocrinol. Metab. 17, 862-869.

17. Pehlivanoğlu, B., Balkanci, Z.D., Ridvanağaoğlu, A.Y., Durmazlar, N., Öztürk, G., Erbaş, D., Okur, H., 2001. Impact of stress, gender and menstrual cycle on immune system: Possible role of nitric oxide. Arch. Physiol. Biochem. 109, 383-387.

18. Reeves, J.T., Zamudio, S., Dahms, T.E., Asmus, I., Braun, B., Butterfield, G.E., McCullough, R.G., Muza, S.R., Rock, P.B., Moore, L.G., 2001. Erythropoiesis in women during 11 days at $4,300 \mathrm{~m}$ is not affected by menstrual cycle phase. J. Appl. Physiol. 91, 2579-2586.

19. Shilpa, N., Itagi, V., Rani, R., 2018. A study of hemoglobin concentration in different phases of menstrual cycle. Int. J. Physiol. 6, 90.

20. Thiyagarajan, D.K., Jeanmonod, R., 2019. Physiology, Menstrual Cycle, StatPearls. StatPearls Publishing.

21. Thongngarm, T., Jenkins, J.K., Ndebele, K., McMurray, R.W., 2003. Estrogen and progesterone modulate monocyte cell cycle progression and apoptosis. Am. J. Reprod. Immunol. 49, 129138.

22. Tikare, S.N., Das, K.K., Dhundasi, S.A., 2008. Blood leukocyte profile in different phases of menstrual cycle. Indian. J. Physiol. Pharmacol. 52, 201-204.

23. Tindall, V.R., 1987. Jeffcoate's principles of Gynecology, $5^{\text {th }} \mathrm{ed}$. Butterworth-Heinemann \& Co Ltd, London.

24. Treloar, A.E., Boynton, R.E., Behn, B.G., Brown, B.W., 1970. Variation of the human menstrual cycle through reproductive life. Int. J. Fertil. 12, 77-126.

25. Usha Rani M D, Y.S., Manjunath N B, P.D., D, Knn.M., 2014. Comparative Study of Hematological and Biochemical Parameters during Different Phases of Menstrual Cycle in Young Healthy Women Aged 18-22 Years, IOSR Journal of Dental and Medical Sciences (IOSR-JDMS) e-ISSN.

26. Van den Heuvel, M.J., Horrocks, J., Bashar, S., Taylor, S., Burke, S., Hatta, K., Lewis, J.E., Croy, B.A., 2005. Menstrual cycle hormones induce changes in functional interactions between lymphocytes and decidual vascular endothelial cells. J. Clin. Endocrinol. Metab. 90(5), 2835-2842. 